\title{
Microstructural Observation and Transcriptome Analysis of Pistil Abortion in 'Li Guang' Apricot
}

Tong Zhao

Gansu Agricultural University

\section{Li Cheng}

Gansu Agricultural University

\section{Cuilian Chen}

Gansu Academy of Forestry Sciences

De Zhang

Gansu Agricultural University

Zhongxing Zhang

Gansu Agricultural University

Shuangcheng Wang

Gansu Agricultural University

Jiqiang Zhang

Gansu Academy of Forestry Scieences

\section{Yanfang Zhu}

Gansu Agricultural University

Yan-xiu Wang ( $\nabla$ wangxy@gsau.edu.cn )

Gansu Agricultural University

\section{Research article}

Keywords: 'Li Guang' apricot; Pistil abortion; Microstructurer; RNA-Seq; Hormonal pathway

Posted Date: January 22nd, 2020

DOI: https://doi.org/10.21203/rs.2.21528/v1

License: (c) (1) This work is licensed under a Creative Commons Attribution 4.0 International License.

Read Full License 


\section{Abstract}

Background: 'Li Guang' apricot, a famous local variety, originated in Dunhuang city, Gansu Province,China. It has a long flowering period and a large amount of flowers, but serious pistil abortion has become one of the key factors affecting the fruit set, yield and quality. The distribution and regulation of hormones play an important role in signal molecules of flower abortion. The critical mechanisms of hormone metabolism and the expression levels of genes involved in these processes are, however, poorly understood. Results: To clarify the critical molecular mechanisms of hormone-induced abortion in apricot, normal and abortive flower buds were taken as materials, the pistil abortion of apricot flower was studied by paraffin section, and the RNA seq was used to identify the genes related to flowering regulation. The pistil style was lower than filament. Microstructure showed that the pollen grains of abortive flowers were decreased sharply, the ovaries shrunk and the ovule primordia developed stagnately. Through RNA-Seq, 6647 differentially expressed genes, including 2543 up-regulated and 4104 down-regulated genes, were identified. According to the KEGG Pathway, the pyruvate metabolism, plant hormone signal transduction, spliceosome, RNA transport, protein processing in endoplasmic reticulum and other metabolic pathways were significantly enriched. It revealed that AUX1, AUX / IAA, TIR1, ARF, GH3 and SAUR, vital genes displayed identical differential expression profiles to auxin transduction pathway, and ABF , SnRK2, PP2C to abscisic acid, JAZ, MYC2 to jasmonic acid. The qRTPCR assay with independent samples showed that the expression levels of these selected genes were basically consistent with RNA-Seq results. Conclusions : In the whole differentiate stage of flower, pistil abortion represent versatile style. In this process, the changes of hormones play an important role in pistil abortion, especially IAA,GA, and CTK. Related genes involved in hormones synthesis expression regulate the content of hormones and to adapt to the occurrence of pistil abortion under adversity. At the same time, the ethylene response signal factor ERF1/2 (DN70415) was up-regulated in normal flowers, which further indicated that ethylene might be the key regulatory factor affecting the abortion of 'Liguang' apricot flowers.

\section{Background}

'Li Guang'apricot (Prunus Armeniaca L. var. glabra Sun S. X.) is a famous local special product of Dunhuang City in Gansu Province, China [1]. It has such characters as cold-resistant, drought-resistant, barren and adaptable, with high economic and ecological benefits. Recently, 'Li Guang' apricot has flourish flowers and seldom fruits, which seriously limits its output, economic benefits and brand management [2]. The results of field investigation showed that the percentage of pistil abortion was very high. It had become a major factor to restrict the yield and quality of 'Li Guang' apricot. Thus, it is significant to study of pistil abortion for the development of apricot industry [3].

Ovary development (ovule development and embryo sac formation), style formation, blocked pollination and fertilization may cause pistil abortion in fruit trees during flower pistil development [4]. Pistil abortion was a common life phenomenon in plant growth and development [5]. Reports on pistil abortion of fruit trees have been found in pomegranate [6], apricot [7], Sorbifolia [8] and other fruit trees. In the study of 
Kernel Apricot [9], the peak period of pistil abortion was from big balloon stage to flowering stage. There are many reasons for different apricot varieties. The ovary was prone to different forms of deformity [10]. Maybe, We should pay attention to the abortion caused by internal reasons [11, 12]. Shiting [13] investigated 'big inlay' fruit plum, and found that the abortion rate of pistil reached $76.3 \%$. Bai Zechen [14] investigated the pistil abortion rate of Apricot Varieties in Xinjiang, and found that the abortion rate of five apricot varieties ranged from $60.4-99.64 \%$. The pistil abortion of fruit trees has various forms and complicated mechanism. It is very important to study the genetic and molecular mechanism of pistil abortion for improving fruit yield and seed quality.

Many studies showed that the abortion of pistil was controlled by many factors, such as gene, endogenous substance and environment. Various environmental and endogenous signals were associated with an array of biochemical and cellular processes during the formation of floral organs [15]. Among the signals, phytohormones were endogenously occurring compounds involved in the floral transition, flowering and floral organ development [16]. Moreover, hormones play a regulatory role in the physiological activities of flower buds, including flower bud initiation [17, 18], differentiation [19, 20], and dormancy $[21,22]$. As a developmental growth regulator, $A B A$ is an excellent candidate to integrate environmental inputs of abiotic stimuli with the timing of floral transition [23]. In Arabidopsis, cytokinin (CTK) was found to promote flowering [24, 25], also gibberellin (GA) promoted germination and cell division [26]. In addition, the polar distribution of auxin regulated the formation of plant embryo sac [27]. CTK affected PIN1 expression by promoting the expression of SPL and AG genes, thereby affecting the development of pistil ovules [28]. To sum up, plant hormone levels are likely to be related to pistil abortion formation.

At present, the research on 'Li Guang' apricot mainly focuses on physiological and biochemical aspects, but the molecular mechanisms associated with pistil abortion were rarely reported, in particular, the hormone metabolism mechanisms are poorly understood [29, 30]. The genomic data of 'Li Guang' apricot is not complete, and it is necessary to analyze the transcriptome for gene discovery and further functional studies. In the past studies on the abortion of pistil, the anatomical structure of the whole development process of pistil was rarely studied. In this experiment, the microstructure of abortive flowers and normal flowers in the development of ' $\mathrm{Li}$ Guang' apricot was observed by paraffin section technique. It is mainly to further understand the pistil development characteristics of 'Li guang' apricot for providing the theoretical reference and guidance about improvement measures of pistil abortion.

\section{Results}

Morphological differences between normal and abortive flowers of 'Li Guang' apricot

The phenotypic characterizations of normal and abortive flowers are shown in Fig. 1. The pistils of abortive flowers were normal in appearance, but the development of the ovary was abnormal(Fig. 1B C). Most of them were characterized by uneven growth points, and the ovary is thin and small. And pistil style was lower than the filament and the style was very shortaFig. 1B-E, C-F》. Besides, the stigma of the 
abortive flowers turned black with obvious twisting marks, curving growth and enlarging unevenly. However, the ovary of normal flowers was magnified, the pistil was higher than the stamen $\mathrm{Fig}$. 1E F区, and it becoming easy to pollinate and bear fruit.

Microstructural observation on the normal and abortive flowers of 'Liguang' Apricot

Observing abortive buds under optical microscope, we found that the cell structure of sepals, petals and anthers had changed: the lower epidermis cells and the middle parenchyma cells of sepals degenerated, the cells between the two vascular bundles decreased and formed depressions(Fig. 2O, P). The other cells of petal tissue degenerated and disintegrated except the upper and lower epidermis cells and vascular

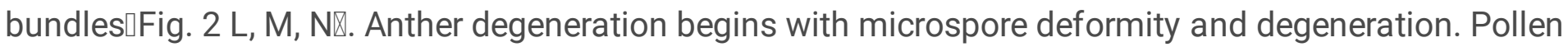
sac shrinks gradually. Cells that form anther wall degenerate, and connective cells degenerate eventually, forming an unorganized mass $\square$ Fig. 2I, N囚. In addition, in the process of bud abortion, ovary tissue degeneration and ovule primordium development were observed[Fig. $2 \mathrm{~J}, \mathrm{~K} \rrbracket$.

Length Distribution of Unigene

The Trinity software De novo Assembly program merged the clean data for floral buds at the two samples to generate the normal and abortive 'Li Guang' apricot transcripts data (Table 1). The transcripts were clustered into 50390 unigenes with a mean length of $1345.51 \mathrm{bp}$, and the N50 value was $1911 \mathrm{bp}$ (Table 1). There were 34366 unigenes of $500 \mathrm{bp}$ and 32272 unigenes of $2000 \mathrm{bp}$. Longer length unigenes enable easier functional annotation and classification. Table 1 provides an overview of the assembled transcripts and unigenes. 
Table 1

Statistical table of assembly results

\begin{tabular}{|lll|}
\hline Length Range & Transcript & Unigene \\
\hline $300-500$ & $34366(22.77 \%)$ & $17683(35.09 \%)$ \\
\hline $500-1000$ & $38609(25.59 \%)$ & $13165(26.13 \%)$ \\
$1000-2000$ & $45655(30.25 \%)$ & $11253(22.33 \%)$ \\
\hline $2000+$ & $32272(21.39 \%)$ & $8289(16.45 \%)$ \\
\hline Total Number & 150902 & 50390 \\
\hline Total Length & 203040054 & 56749958 \\
\hline N50 Length & 1911 & 1769 \\
\hline $\begin{array}{l}\text { Mean Length } \\
\text { Note: Length range: Represents the different length intervals of Transcript/Unigene; the number in }\end{array}$ & \multicolumn{1}{l}{1126.21} \\
\hline $\begin{array}{l}\text { Nranscript/Unigene region represents the number of Transcript/Unigene in corresponding interval, and } \\
\text { the percentage in parentheses represents the proportion of Transcript/Unigene in corresponding } \\
\text { length interval; Total Number: Represents the total number of Transcript/Unigene assembled; Total } \\
\text { Length: Represents the total number of Transcript/Unigene assembled; Total Length: Represents the } \\
\text { number of Transcript/Unigene assembled. The total length of ript/Unigene; N50 Length: the length of } \\
\text { N50 for Transcript/Unigene; Mean Length: the average length of Transcript/Unigene. }\end{array}$ \\
\hline
\end{tabular}

Illumina Sequencing and De novo Assembly of the Transcriptome

Six RNA samples, including three biological replicates from normal flowers' pistil (NF) and abortive flowers' pistil (AF), were subjected to paired-end read sequencing using the Illumina HiSeq 4000 platform to obtain a comprehensive transcriptome. Rigorous quality assessment and data screening generated a total of $93.33 \mathrm{Gbp}$ of clean data (high-quality reads). The clean data of each sample was greater than $2.01 \mathrm{Gbp}$, and more than $91.86 \%$ samples had Phred-like mass fraction at Q30 level (error ,0.1\%) (Table 2). The correlation of the expression levels of biological repetitive genes in samples was an important index to test the reliability of experiments and the correctness of sample selection. In this experiment, the correlation coefficients more than 0.97 , which indicated transcriptome sequencing results were good quality (Fig. 3C). 
Table 2

The total number of sequencing number obtained from each sample

\begin{tabular}{|c|c|c|c|c|c|c|c|}
\hline Sample & Read Sum & Base Sum & GC(\%) & $N(\%)$ & Q20(\%) & CycleQ20(\%) & Q30(\%) \\
\hline NF-1 & 21224213 & $6.37 E+09$ & 47.53 & 0 & 97.06 & 100 & 93.27 \\
\hline NF-2 & 21052439 & $6.32 E+09$ & 47.54 & 0 & 96.46 & 100 & 91.76 \\
\hline NF-3 & 20144456 & $6.04 \mathrm{E}+09$ & 47.55 & 0 & 96.51 & 100 & 91.86 \\
\hline AF-1 & 24749986 & $7.42 \mathrm{E}+09$ & 45.70 & 0 & 97.39 & 100 & 93.28 \\
\hline AF-2 & 31340229 & $9.40 \mathrm{E}+09$ & 45.60 & 0 & 97.55 & 100 & 93.58 \\
\hline AF-3 & 26808194 & $8.04 \mathrm{E}+09$ & 45.52 & 0 & 97.48 & 100 & 93.51 \\
\hline \multicolumn{8}{|c|}{$\begin{array}{l}\text { Note: NF represented normal flower, } \mathrm{AF} \text { represented abortive flower; } 1 \otimes 2 \varangle 3 \text { : three biological replicates } \\
\text { of each stages; } \mathrm{GC} \text { content: percentage of bases of } \mathrm{G} \text { and } \mathrm{C} ; \mathrm{N} \text { means the ambiguous read. Q20 } \\
\text { means the accuracy of base recognition is more than } 99 \% \text {, and Q30 means the accuracy of base } \\
\text { recognition is more than } 99.9 \% \text {. CycleQ } 20 \text { means the cycle whose average quality score is greater } \\
\text { than or equal to } 20 \text {. }\end{array}$} \\
\hline
\end{tabular}

Functional Classification of DEGs

To functionally categorize the up and down-regulated DEGs, the GO, COG, KEGG, KOG, Pfam, Swiss-Prot and $\mathrm{Nr}$ databases were used to annotate the functions of the DEGs (Fig. 3B). According to the COG database(Fig. 3A), the DEGs were functionally clustered into 25 classifications. The top three classifications in NF/AF contained 'general function prediction', 'Translation, ribosomal structure and biogenesis'and 'Transcription'. The smallest groups were 'Chromatin structure and dynamics' and 'Cell motility'.

In addition, GO enrichment of the DEGs in normal and abortive floral was analyzed and it was found that these comparisons were found to be enriched for some specific GO categories (Fig. 4). The main biological processes were translation, photosystem II assembly, pentose-phosphate shunt, protein processing. Cell components were enriched in ribosome, chloroplast thylakoid membrane, preribosome, large subunit precursor, photosystem I reaction center, pollen tube. The most prominent molecular functions are oxidoreductase activity, transferase activity, transferring acyl. chlorophyll binding, threoninetype endopeptidase activity, glyceraldehyde-3-phosphate dehydrogenase. It shows that in the process of flower organ formation, a large number of metabolic pathways changed inside the floral bud tissue, and many new substances were synthesized and the old substances were decomposed, which resulting in great changes in the floral bud morphology. Many components in the cell were metabolized and a large number of enzymes played an important role in the process.

Identification of Differentially Expressed Genes (DEGs) 
Hierarchical clustering analysis was made for the differentially expressed genes. The genes with the same or similar expression behavior were clustered. The clustering results of differentially expressed genes were shown in Fig. 5A. The MA map can be used to visualize the expression level and the overall distribution of the differential multiples of the two groups of genes. The MA map of differentially expressed genes was showed in Fig. 5B.

The FPKM method was used to calculate the expression levels of unigenes in these samples. DESeq software detected a total of 6647 DEGs from normal flowers (NF) and abortive flowers (AF) comparisons. Among them, 2543 were up-regulated and 4104 were down-regulated. We analyzed the transcript abundance of genes, and the results were showed in Fig. 5C. In AF vs NF, 2543 genes were up-regulated, and 4104 genes were down-regulated.

KEGG classifications of unigenes

In order to clarify the biological metabolic pathways of flower buds of 'LiGuang' apricot during this abortion stages, KEGG Pathway was enriched according to the annotation results. The metabolic pathways in the top 20 were showed in Table 3. Pyruvate metabolism, Plant hormone signal transduction, Spliceosome, RNA transport, Protein processing in endoplasmic reticulum and other metabolic pathways were very active. These results showed that the abortion of female flowers was selectively expressed by genes. RNA transcription was followed by variable splicing to produce mRNA, which translated and synthesized functional proteins. Moreover, oxidative phosphorylation, glycolysis pathway and starch and sucrose metabolism maintained the basic life activities of 'Li Guang' apricot and provided material and energy. 
Table 3

KEGG pathway analysis of female flower abortion in 'Li Guang' apricot

\begin{tabular}{|lll|}
\hline KEGG Pathway & ko-ID & DEGs \\
\hline 1. Pyruvate metabolism & ko00620 & 19 \\
\hline 2. Plant hormone signal transduction & ko04075 & 43 \\
\hline 3. Cysteine and methionine metabolism & ko00270 & 15 \\
\hline 4. Phenylalanine metabolism & ko00360 & 24 \\
\hline 5. Glycolysis / Gluconeogenesis & ko00010 & 34 \\
\hline 6. Ubiquitin mediated proteolysis & ko04120 & 27 \\
\hline 7. Biosynthesis of secondary metabolites & ko01110 & 157 \\
\hline 8. ABC transporters & ko02010 & 12 \\
\hline 9. Phenylpropanoid biosynthesis & ko00940 & 29 \\
\hline 10. Pentose and glucuronate interconversions & ko0040 & 12 \\
\hline 11. Biosynthesis of amino acids & ko01230 & 14 \\
\hline 12. Protein processing in endoplasmic reticulum & ko04141 & 51 \\
\hline 13. Oxidative phosphorylation & ko00190 & 43 \\
\hline 14. Starch and sucrose metabolism & ko00500 & 19 \\
\hline 15. Endocytosis & ko04144 & 33 \\
\hline 16. RNA transport & ko03013 & 41 \\
\hline 17. Phenylalanine, tyrosine and tryptophan biosynthesis & ko00400 & 12 \\
\hline 18. Ether lipid metabolism & ko00565 & 14 \\
\hline 19. Protein export & ko03060 & 12 \\
\hline 20. Glutathione metabolism & & 29 \\
\hline
\end{tabular}

Endogenous hormone measurements

The KEGG databases suggested that the DEGs belonged to "plant hormone signal transduction" and accounted for a relatively large portion in all of these comparisons. We analyzed the expression level of plant hormone-related genes and detected the contents of several relevant plant hormones in normal and abortive flowers. Three independent samples collected from different flowers were used for endogenous hormone measurements. As can be seen from the Fig. 6,the CTK content of 'Li Guang' apricot showed an upward trend with time, and there were significant differences. The CTK content of normal flowers was 
significantly higher than that of abortive flowers in the same period, and decreased from $441(\mathrm{ng} / \mathrm{g})$ to $367(\mathrm{ng} / \mathrm{g}$ ) by $20.2 \%$ (Fig. 6A). But the content of GA increased from $249(\mathrm{ng} / \mathrm{g})$ to $231(\mathrm{ng} / \mathrm{g})$, which increased by $16.5 \%$ (Fig. 6B). The change of ABA content was different from other hormones. ABA content of abortive flowers $(415 \mathrm{ng} / \mathrm{g})$ was significantly higher than that of normal flowers $₫ 289 \mathrm{ng} / \mathrm{g} \rrbracket$, which was $43.6 \%$ higher than that of normal flowers (Fig. 6C). The changes of ZR and IAA showed an upward trend, and the contents of ZR and IAA in normal flowers were significantly higher than those in abortive flowers (Fig. 6D E).

DEGs in response to plant hormone signaling pathways

In our study, a large number of hormone-related DEGs were identified between normal and abortive flowers (Additional file 1). The KEGG analysis assigned most of the DEGs to key components involved in various hormonal signaling pathways (Fig. 7). In the auxin signal transduction pathway, three unigenes encoding auxin influx transport protein (AUX1) were found to be differentially expressed, two of which were up-regulated (DN68198, DN68818) and one showed down-regulated mode (DN68818). It was found that seven DEGs encode SAUR, four of them were down-regulated, and one showed up-regulated (DN70283). Only two DEGs were annotated to auxin-induced protein AUX/IAA. In the auxin signal transduction pathway, nine out of the thirteen DEGs were down-regulated, and four of those were upregulated. In the cytokinine signaling pathway, one encoding type-a response regulator (A-ARR) showed down-regulated. In the signal transduction pathway of gibberellin, a differential expression of unigenes encoding gibberellic acid receptor (GID1) was found and identified as down-regulated. In the abscisic acid signal transduction pathway, four of the five showed an up-regulated patten. They encode SNF1-related protein kinase 2 (SnRK2) and ABA reactive element binding factor (ABF). Only Unigene (DN68241) coding abscisic acid receptor showed a down-regulated which encoded type $2 \mathrm{C}$ protein phosphatase (PP2C). In the ethylene signal pathway, two DEGs were also up-regulated, including one unigenes encoding serine/threonine-protein kinase (CTR1), one encoding ein3-binding F-box protein (EBF1/2). In the jasmonic acid signal transduction pathway, three unigenes encoding transcription factor (MYC2) were found to be differentially expressed, two of which were down-regulated (DN69632, DN68836) and one showed up-regulated mode (DN69632). Three Unigenes encoding jasmonate ZIM domain-containing protein (JAZ) showed a down-regulated trend.

Validation of the expression of several key hormone-related genes

To verify the differential expression levels of some key hormone-related genes identified by RNA-seq, a qRT-PCR assay with independent samples collected from normal and abortive flowers was performed (Fig. 8). In total, 16 key flower hormone-related genes. Using 26S rRNA [31] as the internal reference gene, each gene was biologically repeated three times. The expression levels of these selected genes were basically consistent with RNA-seq results. The primer sequences are listed in Additional file 2.

\section{Discussion}


In fruit production,the flower blossom and fruit set were directly decided by normal pistil development [32]. Ovary development, style formation and fertilization process blocked during pistil development may cause pistil abortion in fruit trees. In process of flower organ differentiation of apricot flower, pistil formation is later than stamen, some flower buds only partially differentiate in the growing season, and ovary does not appear until March of the next year [33]. Therefore, before the pistil is fully developed, the ability of stamens to compete for nutrients is particularly strong, which makes the pistil undernourished and incomplete differentiation, leading to pistil abortion of apricot. One of the reasons for empty bracts in Castanea mollissima Blume is female sterility, which is manifested in the stop of megasporocyte development and the abnormal structure of mature embryo sac [34]. In addition, the abortion of Prunus salicina [35] embryo showed that the abortion characteristics of plum embryo mainly include, delayed development of embryo sac, disintegration and degeneration of nucellar integument cells, abnormal structure of mature embryo sac, etc. In this study, the types of pistil abortion of 'Li guang' apricot were ovule degeneration, abnormal development of integument, small ovary or abnormal shape, short style, constriction of style and abnormal stigma surface, among which ovule degeneration was the main type. This is similar to the phenomenon of pistil abortion found in Pomegranate [36] and Sorbifolia [37] fruit trees by predecessors. The development stagnation of ovule may affect the normal development of other components of pistil, but whether there is an inevitable relationship between them remains to be confirmed by further research.

As signals for the communication in plants, hormones have important roles in physiological activities such as metabolism, morphogenesis and growth [38,39]. The plant hormone signals are perceived and transmitted to the nuclear by series signal transduction components to induce gene expression, resulting in a series of physiological processes [40]. At present, several studies have shown that endogenous hormones, such as IAA, cytokinins, GA3 and ABA, regulate pistil development [41, 42]. In our study, a large number of hormone-related DEGs were identified between normal and abortive flowers. Based on the DEGs analysis, auxin related genes, including ARFs, AUX/IAAs, and GHs, were identified as DEGs. Auxin is one of the most important plant hormones, because it regulates growth and development in diverse ways $[43,44]$. Auxin-resist-ANT1s (AUX1), transport inhibitor response1 (TIR1), AUX/IAA, auxin response factor (ARF), GH3, and small auxin up RNAs (SAUR) are key genes involved in the auxin signal transduction pathway [45]. Auxin promotes TIR1 and AUX/IAA interaction [46, 47]. The Arabidopsis TFs ARF6 and ARF8 are expressed in multiple flower tissues, such as sepals, petals and stamen filaments [48]. Moreover, these two genes function in different organs to promote the transition from closed buds to mature normal flowers. At low auxin levels, AUX/IAA proteins bind to ARFs and suppress ARF function [49]. In the current study, AUX1(DN68818), AUX/IAA (DN70853, DN68398), ARF (DN71836) and SAURs (DN71004, DN69270, DN69226, DN50721), which were significantly up-regulated in NF compared with AF, were considered to be able to promote cell enlargement and plant growth and development. These findings are consistent with previous study [50]. At the same time, the content of IAA in normal flowers was significantly higher than that in abortive flowers. Thus, auxin and auxin transport may be required for floral meristem determinacy and flower patterning in 'Li Guang' apricot. 
In pistil primordia, CTK was specifically synthesized at meristem at the pericarpal margin of the carpel, and then appeared at the diaphragm primordia, the medial conducting tissue of the diaphragm and the valve margin of the mature pistil [51]. The increase of the content of pistil cytokinin can increase the pistil morphology and the number of ovules [52]. The results showed that the CTK content of normal flowers was significantly higher than that of abortive flowers. In CTK metabolic pathway, A-ARR gene differences were down-regulated, A-ARR acted as a positive regulator of CTK to transcribe downstream target genes. The down-regulation of A-ARR gene in metabolic pathway may be a positive regulatory response to the decrease of CTK content in pistil, which is also one of the important causes of pistil abortion. The serious imbalance of IAA and CTK in the proportion of plants may also be an important reason for their abortion [53]. As a positive regulator of CTK signaling [54], AHP is involved in the activation of ARRS [55]. Consistent with this finding, the expression of A-RRA (DN66675) was also higher in normal flowers. Therefore, the expression of genes promoted the content of CTK in normal flowers to be higher than that in abortive flowers. Thus, CTK has been shown to promote the formation of flower organs in this study. Also, ZR is a kind of cytokinin. Previous studies on the relationship between ZR and flowering mostly believed that high level of ZR was beneficial to flower bud differentiation [56]. The results showed that the ZR content of the normal flowers was significantly higher than that of the abortive flowers, which indicated that the high ZR content was helpful to the formation of flower organs in a certain range. It is consistent with the previous research results.

In additional, GA3 play important roles in flower development. GA3 regulates sex differentiation in plants, inhibits pistil development at an appropriate level. [57, 58]. An RNA-seq transcriptome analysis suggested that the morphology of grape inflorescences may be controlled by the biosynthesis and signaling of GA3 [59]. Also in Arabidopsis, a GA-deficient mutant, ga1-3, displayed the retarded growth of four whorls in the floral organs, and its flower phenotypes could be rescued by the application of exogenous GA [60]. In our study, one GID-encoding genes were identified as DEGs, suggesting an involvement of GA signaling in 'Li Guang' apricot flower development. The results showed that the normal flowers had lower GA3 content, which was consistent with the expression level of hormone related genes in normal flowers. G1D1 (GA metabolism gene) is highly expressed in normal flowers, which may be due to the fact that G1D1 reduces the biological activity of GA, resulting in the low content of GA3.

$A B A$ is an important hormone because it plays a key regulatory role in different stages of plant life cycle related to seed development, flower and phase transition, and plant response to environmental stress [61]. In Arabidopsis, ABA promotes flower bud formation by regulating photoperiod response genes and flowering genes. ABA can also inhibit the formation of flower organs independently of floral genes [62]. In the study of olive, apple and longan, the endogenous hormone ABA can inhibit flower formation $[63,64]$. Our data confirmed that ABA-related genes also showed significant expression changes between normal and abortive flowers. ABA-responsive transcripts SnRK2 and ABF, were significantly up-regulated in AF compared with those of NF. These genes have been reported to be activated by abiotic stress conditions, and they can adapt to the adverse environment by regulating $A B A[65,66]$. Also, we found that $A B A$ content in abortive flowers increased significantly, which was significantly higher than that in normal flowers. Thus, the lower content of ABA may also be one of the causes of pistil abortion. 
Ethylene contributes to pistil development. EBF transcription factor is a member of AP2 gene family, and its encoded protein has negative regulation on AGAMOUS gene $[67,68]$. The results show that ethylene is the upstream regulator of tobacco ovule development and plays a key role in ovule development [69]. In the process of abortion of 'Li Guang' apricot flowers, transcriptome analysis revealed that the expression of ethylene response signal molecules was differentially expressed between normal and abortive flowers. At the same time, the ethylene response signal factor ERF1/2 (DN70415) was up-regulated in the normal flowers, which further indicated that ethylene might be the key regulatory factor affecting the pistil abortion of 'Liguang' apricot.

Mutations in genes that participate in JA biosynthesis and perception caused a failure or delay in anther dehiscence and pollen inviability which result in female sterility [70]. Defects in all stages of the JA pathway appeared to cause similar phenotypes of reduced filament elongation and a lack of dehiscence. Delayed dehiscence and non-dehiscence phenotypes have been observed in mutants defective in JA biosynthetic enzymes [71]. In this study, Jasmonate-zim-domain (JAZ; DN70420, DN68654, DN64953) were up-regulated in NF compared with those in $\mathrm{AF}$, and were involved in the regulation of JA mediated signaling pathway. Myelocytomatosis (MYC2: DN68836, DN69632), which was involved in the regulation of defense response to stress, was also up-regulated in NF compared with those in AF. JA was specifically required for anther dehiscence during anther development. These gene mutations involved in JA synthesis pathway may lead to the occurrence of pistil abortion, which is consistent with previous research results.

\section{Conclusions}

RNA-seq were used first time to analyze differences gene expression in normal and abortive floral buds of 'Li Guang' apricot during flower differentiation. 6647 DEGs were detected in different comparisons. we focused on the expression trend of several plant hormone-related regulatory genes. These results will facilitate future analyses of the role of these genes in flower development. In the whole differentiate stage of flower, pistil abortion represent versatile style. In this process, the changes of hormones play an important role in pistil abortion, especially IAA,GA,and CTK. Related genes involved in hormones synthesis expression regulate the content of hormones and to adapt to the occurrence of pistil abortion under adversity. At the same time, the ethylene response signal factor ERF1/2 (DN70415) was upregulated in normal flowers, which further indicated that ethylene might be the key regulatory factor affecting the abortion of 'Liguang' apricot flowers.

\section{Methods}

\section{General Situation of the Test Site}

The experiment was conducted in Heshui village, Dunhuang City, Gansu Province, China, from February to

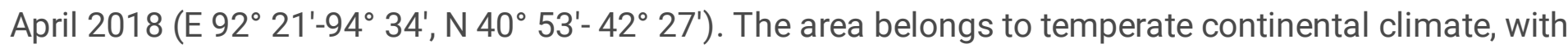
an average annual precipitation of $32 \mathrm{~mm}$, evaporation of $2522 \mathrm{~mm}$, annual sunshine hours of 3246.7, 
annual average temperature of $9.4^{\circ} \mathrm{C}$, monthly average maximum temperature of $24.9^{\circ} \mathrm{C}$ (July), monthly average minimum temperature of $-9.3^{\circ} \mathrm{C}$ (January), annual average frost-free period of 142 days. The planting soil is irrigation soil and silt soil.

Plant materials and experimental design

In our study, 8-year-old 'Li Guang' apricot (Prunus Armeniaca L. var. glabra Sun S. X.) was used as the experimental material ('Li Guang' apricot was introduced from Hetian, Xinjiang. After a long period of natural domestication and artificial cultivation, it was a special variety in Dunhuang. 'Li Guang' apricot identification has been confirmed in fruit trees of Gansu Province. ) . The density is $2.0 \times 3.0 \mathrm{~m}$, the diameter of trunk is $13.0-17.0 \mathrm{~cm}$, and the height of the tree is $1.5-2.2 \mathrm{~m}$. Drainage ditches were set up between rows and conventional management was adopted in the field. The flowers before open were collected from a normal flower (NF) and an abortion flower (AF). All fresh flower samples were collected simultaneously, transferred immediately to liquid nitrogen, and stored at $-80^{\circ} \mathrm{C}$ for RNA extraction and hormone determination. All of the flower samples were harvested from three trees as three independent biological replicates.

Measurement of Test Indicators

Histological Observation

Verification of the microstructure of normal and abortive floral buds was performed using paraffin sections based on the methods [72]. Photographs of fresh samples were taken using a stereomicroscope. Samples were placed into FAA fixative for $24 \mathrm{~h}$ and placed in a vacuum environment to promote fixative penetration. Samples were dehydrated in a continuous gradient of alcohol and embedded into paraffin blocks. Samples were cut into 6.0-10.0 mm using a rotary microtome. Samples were deparaffinized, stained with hematine, and mounted with neutral resins. We observed the slices and obtained photographs using an Olympus BX53 microscope (Olympus, Tokyo, Japan).

Hormone determination

The content of plant hormone was determined by HPLC [73]. Three biological repeats were collected from each time node.

Library preparation for Transcriptome sequencing

A total amount of $3 \mu \mathrm{g}$ RNA per sample was used as input material for the RNA sample preparations. Sequencing libraries were generated using NEBNext ${ }^{\circledR}$ UltraTM RNA Library Prep Kit for Illumina ${ }^{\circledR}$ (NEB, USA) following manufacturer's recommendations and index codes were added to attribute sequences to each sample. Briefly, mRNA was purified from total RNA using poly-T oligo-attached magnetic beads [74, 75]. Fragmentation was carried out using divalent cations under elevated temperature in NEBNext First Strand Synthesis Reaction Buffer(5X). First strand cDNA was synthesized using random hexamer primer and M-MuLV Reverse Transcriptase (RNase H-). Second strand cDNA synthesis was subsequently 
performed using DNA Polymerase I and RNase $\mathrm{H}$. Remaining overhangs were converted into blunt ends via exonuclease/polymerase activities. After adenylation of 3' ends of DNA fragments, NEBNext Adaptor with hairpin loop structure were ligated to prepare for hybridization. In order to select cDNA fragments of preferentially $250 \sim 300 \mathrm{bp}$ in length, the library fragments were purified with AMPure XP system (Beckman Coulter, Beverly, USA). Then $3 \mu$ I USER Enzyme (NEB, USA) was used with size-selected, adaptor-ligated cDNA at $37^{\circ} \mathrm{C}$ for 15 min followed by 5 min at $95^{\circ} \mathrm{C}$ before PCR. Then PCR was performed with Phusion High-Fidelity DNA polymerase, Universal PCR primers and Index (X) Primer. At last, PCR products were purified (AMPure XP system) and library quality was assessed on the Agilent Bioanalyzer 2100 system [76, 77] .

Quality control

Raw data (raw reads) of format were firstly processed through in-house perl scripts. In this step, clean data (clean reads) were obtained by removing reads containing adapter, reads containing ploy- $\mathrm{N}$ and low quality reads from raw data. At the same time, Q20, Q30 and GC content the clean data were calculated. All the downstream analyses were based on the clean data with high quality.

Quantification of gene expression level

Feature Counts v1.5.0-p3 was used to count the reads numbers mapped to each gene. And then FPKM of each gene was calculated based on the length of the gene and reads count mapped to this gene. FPKM, expected number of Fragments Per Kilobase of transcript sequence per Millions base pairs sequenced, considers the effect of sequencing depth and gene length for the reads count at the same time, and is currently the most commonly used method for estimating gene expression levels.

Differential expression analysis

Differential expression analysis of two conditions/groups (three biological replicates per condition) was performed using the DESeq2 R package (1.16.1). DESeq2 provide statistical routines for determining differential expression in digital gene expression data using a model based on the negative binomial distribution. The resulting P-values were adjusted using the Benjamini and Hochberg's approach for controlling the false discovery rate. Genes with an adjusted P-value $<0.05$ found by DESeq2 were assigned as differentially expressed [78] .

Quantitative real-time PCR

cDNA was synthesized from total RNA using the PrimeScript ${ }^{\text {TM }}$ RT reagent Kit with gDNA Eraser (Perfect Real Time) (TaKaRa, Dalian, China). Quantitative real-time PCR was performed using a Light Cycler® 96 Instrument (Roche, Shanghai, China) with $26 \mathrm{~s}$ as a reference gene. Measurements for each plate were replicated three times.

Statistical analyses 
Data were analyzed using the statistical software SPSS 22.0 (SPSS, Chicago, IL, USA), Differences between means of treatments were performed by the Duncan's multiple test at $P<0.05$. Charts were made using Origin 8.0 software. Primer pairs were designed using DNAMAN.

\section{Abbreviations}

NF: Normal flowers; AF: Abortive flowers; ST: Stigma; AN: Anther; PE: Petal; Fl: Filament; O: Ovary; OP: Ovule primordium; AN: Anther; PP: Pistil primordium; SP: Sepal; ST: Stamen primordium; UE: Upper epidermis; LE: Lower epidermis; VB: Vascular bundle; PS: Pollen sac; MI: Microspore mother cell; GO: Gene ontology; KEGG: Kyoto encyclopedia of genes and genomes; COG: Cluster of orthologous groups of proteins; qRT-PCR: Quantitative real-time PCR; RNA-Seq: RNA sequencing; DEGs: differentially expressed genes; IAA: Indole acetic acid; CTK: Cytokinin; ABA: Abscisic acid; GA: Gibberellin; ZR: Zeatin ribosid.

\section{Declarations}

\section{Ethics approval and consent to participate}

Not applicable

\section{Consent for publication}

Not applicable

\section{Competing interests}

The authors declare that they have no competing interests.

\section{Funding}

This work was supported by the key R \& D program of Gansu Provincial Science and Technology Department (17YF1NA054). The financial support provided by the project ensured the sequencing of transcriptome and the implementation of various works. It ensured that we obtained pure plant materials and the accuracy of the experiment.

\section{Authors' contributions}

YXW collected plant materials and designed the experiment. YXW and TZ wrote the manuscript. TZ, LC and CLC collected data and performed the experiments. YXW helped to draft and revise the manuscript. All authors read and approved the final manuscript.

\section{Acknowledgements}

Not applicable 


\section{References}

1. Liu ZH, Liu JM. High-quality and high-efficiency cultivation techniques of Li Guangxing. Scientific breeding. 2019; (03): 26-28. 2. Chen CL, Zhang JQ, Zhao T, Zhu ZL, Liu SH, Guo R, Ma CS. The effect of Topdressing Nitrogen Fertilizer on the nutrition and photosynthetic characteristics of 'Li Guangxing' tree. Economic forest research, 2019;37 (02): 13-22. 3. Qin ZY, Liu SH, Ma HL, Ma XW. Early-fruiting and highyield cultivation techniques of Liguang apricot in Dunhuang, Gansu. Practical techniques and information of fruit trees.2017; (03): 10-12. 4. Wetzstein H Y, Ravid N, Wilkins E, Adriana P M. A morphological and histological characterization of bisexual and male flower types in pomegranate [J]. Journal of the American Society for Horticultural Science, 2011;136(2): 83-92. 5. Brown R H, Nickrent D L, Gasser C S. Expression of ovule and integument-associated genes in reduced ovules of Santalales. Evolution \& Development. 2010;12(2): 231-240. 6. Wetzsteini, HY, Yi, et al. Flower Position and Size Impact Ovule Number per Flower, Fruitset, and Fruit Size in Pomegranate. J AM SOC HORTIC SCI.2013. 7. J. Rodrigo, M. Herrero, J.I. Hormaza. Pistil traits and flower fate in apricot (Prunus armeniaca). Annals of Applied Biology. 2009;154. 8. Zhang M, Wang Q, Zhang L, Tang L, Wang Li. Morphological structure comparison of male and female flower development in Xanthoceras sorbifolia . Journal of electron microscopy. 2012;31 (02): 154-162. 9. Wei YJ, Liao K, Li WW, Feng BB, Xu YS, Wang M, Yang HL, and Niu YY. An anatomical study on flowerbud differentiation in Prunus salicina xarmeniaca, GuoshuXuebao (Journal of Fruit Tree).2017;34(7): 843-850. 10. Li L, and Ma FW, Morphological studies on flower buddifferentiation in different apricot varieties, Xibei NonglinKeji Daxue Xuebao (Journal of Northwest Sci-Tech Univer-sity of Agriculture and Forestry (Natural Science Edition)).2001;29(2): 105-108. 11. Shen HX, Kong Y, Yao YC, Zhang R, and Fu ZF, Research progress on apricot pistil abortion. Zhongguo Guo-shu (China Fruits). 2007; (3): 57-59. [12]Chen LN, Xue H, Niu J, Li HX, Zhang J, Li C, Zhang FH,Zhao DG, Liu BB, Wang Q, and Cao SY, Researchprogress on pistil abortion in fruit trees, Guoshu Xuebao(Journal of Fruit Tree). 2007;33(9): 1156-1163. 13. Shi T, Zhang QL, Gao ZH, Zhang Z, Zhuang WB. Analysis of pistil differentiation process and related biochemical indexes of two fruit plum varieties. Journal of plant resources and environment. 2011;20 (04): 35-41. 14. Bai ZC, Feng JR, Li WH, Hu YY, Cao XY, Sun JL. Investigation on pistil abortion rate of five cultivated Apricot Varieties in Xinjiang . Xinjiang Agricultural Science.2012;49 (10): 1805-1809 + 1823. 15. Wang ZX, Jiao ZQ, Ai J, Model Shutian, Yang YM, Shen YJ. Study on stamen and pistil abortion of grape male flowers. Hebei Forestry Science and Technology. 2014 ; 63-65. 16. Davis SJ. Integrating hormones into the floral-transition pathway of Arabidopsis thaliana. Plant Cell Environ. 2009;32(9):1201-10. 17. Dubois, A, Remay, A, Raymond, O, Balzergue, S,Chauvet, A, Maene, M . Bendahmane, M. Genomic approach to study floral development genes in Rosa sp. Plos one. 2011;6(12), e28455. 18. Zhang D, Ren L, Yue J, Wang L, Zhuo L and Shen X. A comprehensive analysis of flowering transition in Agapanthus praecox ssp. Orientalis (Leighton) Leighton by using transcriptomic and proteomic techniques. Journal of Proteomics. 2013;80; 1-25. 19. Lin L, Huang Y, Xie, T, Zhang Y, Zhou $Y$ and Wen R. Changes of endogenous hormone content during flower bud differentiation in three grape varieties. Journal of Southern Agriculture. 2012; 06; 806-809 . 20. Fu C, Huang, N, Li S, Zhao Z, Huang Z, Shi Y and Tang F. Endogenous hormones contents and growth development in south Fengshui pear. Southwest China Journal of Agricultural Sciences. 2012;01;276-279. 21. Bai S, Saito T, Sakamoto 
D, Fujii $\mathrm{H}$ and Moriguchi T . Transcriptome analysis of Japanese pear (Pyrus pyrifolia Nakai.) flower buds transitioning through endodormancy. Plant and Cell Physiology. 2013;54; 1132-1151. 22. Zhu Y, Li Y, Xin D, Chen W, Shao X, Wang Y and Guo W. RNA-Seq-based transcriptome analysis of dormant flower buds of Chinese cherry (Prunus pseudocerasus). Gene. 2015;555(2); 362-376. 23. Jacobsen J V, Pearce D W, Poole A T, Pharis R P and Mander L N . Abscisic acid, phaseic acid and gibberellin contents associated with dormancy and germination in barley. Physiologia Plantarum. 2002;115(3);428-441. 24. Bartrina I, Otto $E$, Strnad M, Werner T and Schmülling $T$. Cytokinin regulates the activity of reproductive meristems, flower organ size, ovule formation, and thus seed yield in Arabidopsis thaliana. The Plant Cell.2011; 23(1); 69-80. 25. Corbesier L, Prinsen E, Jacqmard A, Lejeune P, Van Onckelen H, Périlleux C and Bernier G. Cytokinin levels in leaves, leaf exudate and shoot apical meristem of Arabidopsis thaliana during floral transition. Journal of Experimental Botany.2003; 54(392); 2511-2517. 26. Debeaujon I and Koornneef M . Gibberellin requirement for Arabidopsis seed germination is determined both by testa characteristics and embryonic abscisic acid. Plant Physiology. 2000; 122(2): 415-424. 27. Pagnussat G C, Alandete-Saez M, Bowman J L, Sundaresan V. Auxin-dependent patterning and gamete specification in the Arabidopsis female gametophyte. Science. 2009; 324; 1684-1689. 28. Bencivenga S, Simonini S, Benková E, Colombo L. The transcription factors BEL1 and SPL are required for cytokinin and auxin signaling during ovule development in Arabidopsis . The Plant Cell. 2012; 24 : 2886-2897. 29. Chen C, Chen G, Cao B, Lei J. Transcriptional profiling analysis of genic male sterile-normal Capsicum annuum reveal candidate genes for pollen development and maturation by RNA-Seq technology. Plant Cell, Tissue and Organ Culture (PCTOC). 2015; 122(2): 465-476. 30. Miao YZ. Zhu Q. Guo Y. Zhu X. Yang et al. Transcriptome Analysis of Differentially Expressed Genes Provides Insight into Stolon Formation in Tulipa edulis. Front. Plant Sci. 2016;7(e67116): 409. 31. Marty, I. Ethylene regulation of carotenoid accumulation and carotenogenic gene expression in colour-contrasted apricot varieties (Prunus armeniaca)[J]. Journal of Experimental Botany. 2005;56(417):1877-1886. 32. Jiang XF, Wang LR, Zou ZR, Zhu GR, Fang WC. Anatomical study on the pistil abortion characteristics of Baihuashan green peach . Journal of fruit trees. 2004 ;(03): 201-203. 33. Galimba K D, DI Stilio V S. Sub-functionalization to ovule development following duplication of a floral organ identity gene [J]. Developmental Biology. 2015; 405 (1): 158-172. 34. Chen F, Su SH. Microsporogenesis and development of male and female gametophytes of 'Zunyu' chestnut . Economic forest research. 2015;33 (03): 44-49. 35. Yao JL, Fu CH, Hu CG. Study on the abortion phenomenon in the embryo development of $\mathrm{Li}$. Journal of Huazhong Agricultural University. 2000 ; (01): 71-73 + 92. 36. Wetzstein H Y,Yi W, Porter J A. Flower position and size impact ovule number per flower, fruitset, and fruit size in pomegranate. Journal of the American Society for Horticultural Science.2013;138 (3):159-166. 37. Zhang M,Wang D, Zhang L, LÜ XQ,Tang L, Wang L. Comparative of the morphology differences of Sorbifolia male and female flowers during the development of them. Journal of Chinese Electron Microscopy Society. 2012;31(2):154-162. 38. Liscum E, Reed JW . Genetics of Aux/IAA and ARF action in plant growth and development. Plant Mol Biol. 2002;49(3):387-400. 39. Liu Y, Wang QS, Ding YF, Li GH, Xu JX, Wang SH . Effects of external ABA, GA3 and NAA on the tiller bud outgrowth of rice is related to changes in endogenous hormones. Plant Growth Regul. 2011;65(2):247254. 40. Balanzá V, Navarrete M, Trigueros M. Patterning the female side of Arabidopsis: the importance of hormones. Journal of Experimental Botany. 2006;57, 3457-3469. 41. Kariali E, Mohapatra P. 
Hormonal regulation of tiller dynamics in differentially-tillering rice cultivars. Plant Growth Regul .2007; 65(2):247-254. 42. Liscum E, Reed JW. Genetics of Aux/IAA and ARF action in plant growth and development. Plant Mol Biol.2002; 49(3):387-400. 43. Seo H, Kriechbaumer V, Park WJ. Modern quantitative analytical tools and biosensors for functional studies of auxin. J Plant Biol. 2016;59(2):93104. 44. Sorce $C$, Montanaro G, Bottega S, Spanò C . Indole-3-acetic acid metabolism and growth in young kiwifruit berry. Plant Growth Regul.2016; (9):1-11. 45. Wójcikowska B, Gaj MD. Expression profiling of AUXIN RESPONSE FACTOR genes during somatic embryogenesis induction in Arabidopsis. Plant Cell Rep.2016;1-16. 46. Dreher KA, Brown J, Saw RE, Callis J. The Arabidopsis aux/IAA protein family has diversified in degradation and auxin responsiveness. Plant Cell. 2006;18:699-714. 47. Wang R, Estelle M. Diversity and specificity: auxin perception and signaling through the TIR1/AFB pathway. Curr. Opin Plant Biol.2014; 21:51-58. 48. Nagpal P, Ellis CM, Weber H, Ploense SE, Barkawi LS, Guilfoyle TJ, et al. Auxinresponse factors ARF6 and ARF8 promote jasmonic acid production and flower maturation. Development. 2005;132(18):4107-18. 49. Wang R, Estelle M. Diversity and specificity: auxin perception and signaling through the TIR1/AFB pathway. Curr. Opin Plant Biol. 2014; 21:51-58. 50. Li GF, Ma JJ, Tan M, Mao JP, An N, Sha GL, Zhang D, Zhao CP, Han MY. Transcriptome analysis reveals the effects of sugar metabolism and auxin and cytokinin signaling pathways on root growth and development of grafted apple. BMC Genom.2014; 17:150. 51. Theissen G. Development of floral organ identity: stories from the MADS house. Curr Opin Plant Biol. 2001;4(1):75-85. 52. Liu GQ, Li WS, Zheng PH, Xu T, Chen LJ, Liu DF, Hussain S, Teng YW:Transcriptomic analysis of 'Suli' pear (Pyrus pyrifolia white pear group) buds during the dormancy by RNA-Seq. BMC Genomics. 2012, 13:700. 53. Bencivenga S, Simonini S, Benková E, Colombo L. The transcription factors BEL1 and SPL are required for cytokinin and auxin signaling during ovule development in Arabidopsis[J]. The Plant Cell. 2012; 24 (7): 2886-2897. 54. Hutchison, C. E, Li, J, Argueso, C. The Arabidopsis Histidine Phosphotransfer Proteins Are Redundant Positive Regulators of Cytokinin Signaling[J]. Plant Cell. 2018(11):3073-3087. 55. Verma V , Sivaraman J , Kumar P P . Expression, purification, and characterization of cytokinin signaling intermediates:

Arabidopsis histidine phosphotransfer protein 1 (AHP1) and AHP2[J]. Plant Cell Reports. 2013; 32(6):795805. 56. Pang Fuhua, Zhao mizhen, Wang Yu, Yu Hongmei, Xia Jin. Flower bud differentiation and changes of biochemical substances in 'Ningyu' Strawberry. Journal of fruit trees. 2014;31 (06): 1117$1122+1201$. 57. Deng wen C, Fei W, Aiqin G, et al. Effects of GA3 and ethylene on abortion of apricot flower. Acta Agriculturae Boreali-occidentalis Sinica. 2001. 58. Wei yongzan, Dong Chen, Wang Yi, Zheng Xuewen, Li Weicai. The effect of Uniconazole on endogenous hormones in Litchi flower development. Journal of tropical crops. 2017;38 (07): 1188-1192.. 59. Cheng C, Jiao C, Singer SD, Gao M, Xu X, Zhou Y, et al. Gibberellin-induced changes in the transcriptome of grapevine (Vitis labrusca x V. vinifera) cv. Kyoho flowers. BMC Genomics. 2015;16:128. 60. Pearce S, Huttly AK, Prosser IM, Li YD, Vaughan SP, Gallova B, et al.Heterologous expression and transcript analysis of gibberellin biosynthetic genes of grasses reveals novel functionality in the GA3ox family. BMC Plant Biol. 2015;15:130. 61. Li L, Zhang W, Zhang L, Li N, Peng J, Wang Y, et al. Transcriptomic insights into antagonistic effects of gibberellin and abscisic acid on petal growth in Gerbera hybrida. Front Plant Sci. 2015;6:168. 62. Riboni M, Test A R, Galbiati M, et al. ABA-dependent control of GIGANTEA signalling enables drought escape via up-regulation of FLOWERING LOCUS T in Arabidopsis thaliana . Journal of Experimental Botany. 2016; 67(22):6309-6322. 63. Meng 
Yun, Ma Shaofeng, Shao Jianzhu, Sun Jian, Ma Baokun, Wang Hongning. The effect of 6-BA on the germination of axillary buds and endogenous hormones of 'Tianhong 2' apple seedlings . Journal of horticulture. 2012;39 (05): 837-844. 64. Zhu ZJ, Jiang CY, Shi YH, Chen WQ, Chen NL, Zhao MJ, Wu WJ. Changes of endogenous hormones in lateral buds during flower induction and flower bud differentiation of olive . Forestry science, 2015;51 (11): 32-39. 65. The Snf1-related protein kinases SnRK2.4 and SnRK2.10 are involved in maintenance of root system architecture during salt stress. The Plant Journal. 2012;72(3):436-449. 66. Takuya Y, Yasunari F, Kyonoshin M. Four Arabidopsis AREB/ABF transcription factors function predominantly in gene expression downstream of SnRK2 kinases in abscisic acid signalling in response to osmotic stress . Plant Cell \& Environment. 2015;38(1). 67. Boualem A, Fergany M, Fernandez R, Troadec C, Martin A, Morin H. A conserved mutation in an ethylene biosynthesis enzyme leads to andromonoecy in melons . Science. 2008;321(5890): 836-838. 68. Licausi F, Ohme-Takagi M, Perata P. APETALA2/Ethylene Responsive Factor (AP2/ERF) transcription factors: mediators of stress responses and developmental programs . New Phytologist. 2013; 199(3): 639-649. 69. Kaursawhney R, Tiburcio A F, Galston A W. Spermidine and flower-bud differentiation in thin-layer explants of tobacco. Planta. 1988; 173(2):282-284. 70. Shih C F , Hsu W H , Peng Y J , et al. The NAC-like gene ANTHER INDEHISCENCE FACTOR acts as a repressor that controls anther dehiscence by regulating genes in the jasmonate biosynthesis pathway in Arabidopsis[J]. Journal of Experimental Botany.2014; 65(2):621-639. 71. Kong F, Abe J, Takahashi K, et al. Allene oxide cyclase is essential for theobroxide-induced jasmonic acid biosynthesis in Pharbitis nil[J]. Biochemical \& Biophysical Research Communications. 2005; 336(4):1150-1156. 72. Meresz P, Kristof Z, Németh-Szerdahelyi E, et al. Ripening and microstructure of apricot (Prunus Armeniaca L.). Acta Alimentaria.2008;37(1):23-39. 73. Wang Jinqiang, Li Huan, Liu Qing, Zeng Lusheng. Effects of spraying exogenous plant hormones on physiological characteristics and yield of sweet potato under drought stress . Journal of Applied Ecology. 2020;1-13. 74. Parkhomchuk D, Borodina T, Amstislavskiy V, et al. Transcriptome analysis by strand-specific sequencing of complementary DNA . Nucleic acids research. 2009; 37(18): e123-e123. 75. Andrews S. FastQC: A quality control tool for high throughput sequence data. Reference Source.2010. 76. Trapnell C, Pachter L, Salzberg S L. TopHat: discovering splice junctions with RNA-Seq[J]. Bioinformatics. 2009; 25(9): 11051111. 77. Daehwan Kim, Ben Langmead, Steven L Salzberg.HISAT: a fast spliced aligner with low memory requirements. Nature methods. 2015;12: 357-360.(HISAT) 78. Love M I, Huber W, Anders S. Moderated estimation of fold change and dispersion for RNA-seq data with DESeq2[J]. Genome biology. 2014;15(12): 1-21.(DESeq2)

\section{Figures}




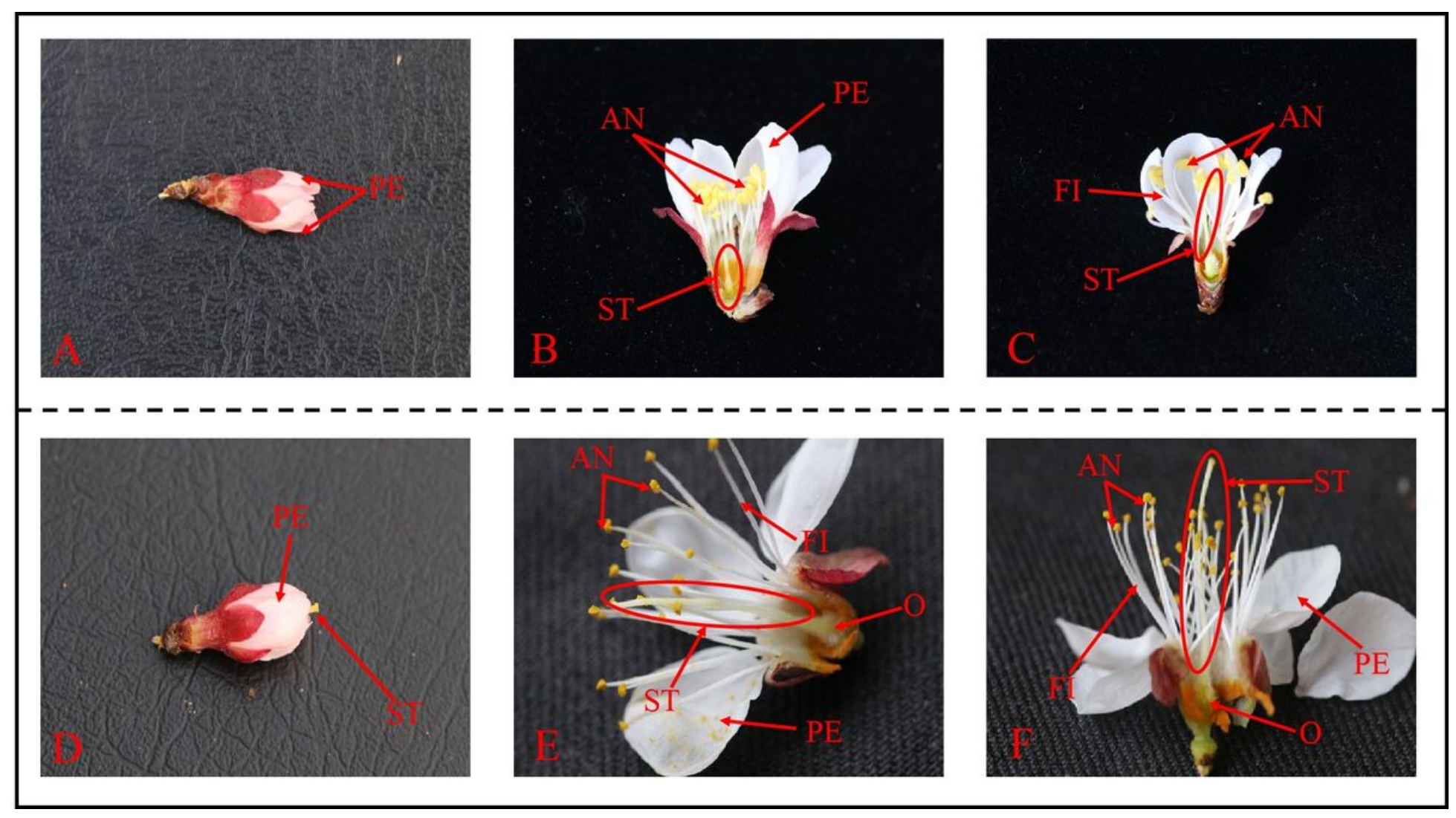

Figure 1

Morphological differences between normal and abortive flowers A, B, C: Normal Flowers; D, E, F: Abortive Flowers; ST: stigma; AN: anther; PE: petal; FI: filament; O: ovary 

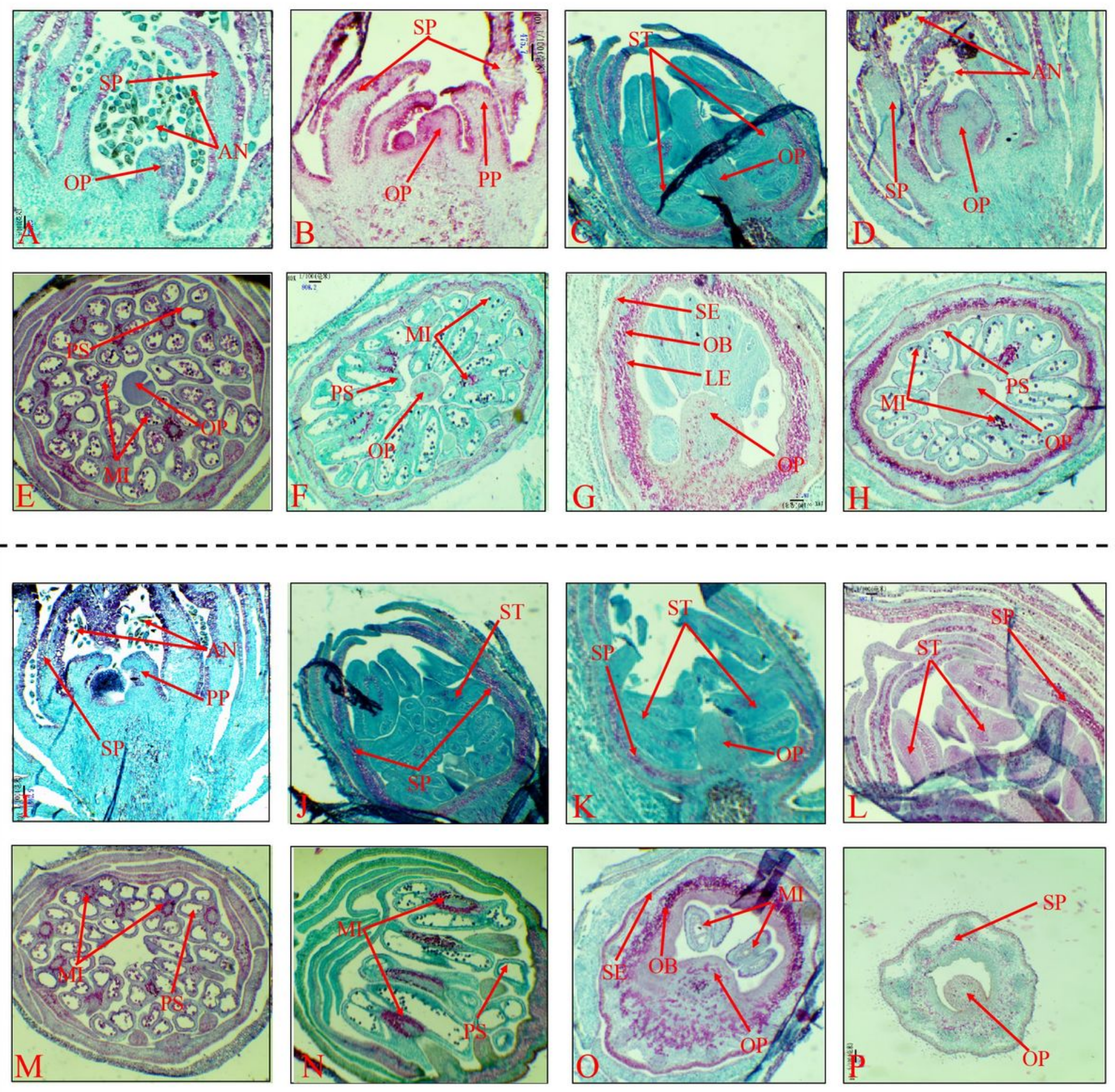

Figure 2

Section diagram of normal and abortive flower A, B, C, D: normal flowers (vertical cut); E, F, G, H: normal flowers (cross cut); I, J, K, L: abortive flowers (Vertical cut); M, N, O, P: abortive flowers (Transverse cut); OP: ovule primordium; AN: anther; PP: pistil primordium; SP: sepal; ST: stamen primordium; UE: upper epidermis; LE: lower epidermis; VB: vascular bundle; PS: pollen sac; MI: microspore mother cell 


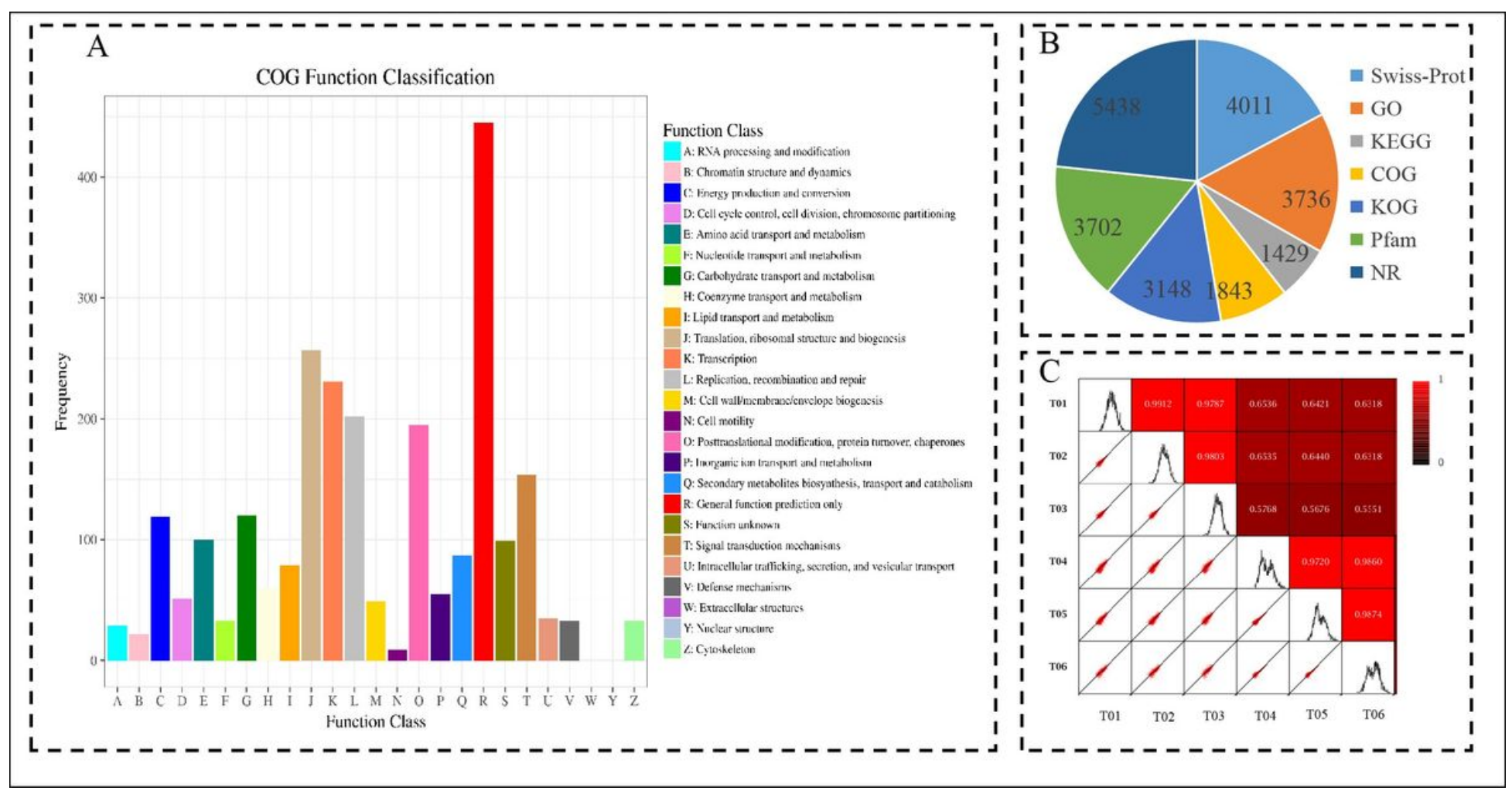

\section{Figure 3}

A: Classification of COG Annotations of Differentially Expressed Genes. Note: The abscissa is the classification content of $C O G$, and the ordinate is the number of genes. In different functional classes, the proportion of genes reflects the corresponding period and environment.Metabolism or physiological biases can be explained scientifically according to the distribution of research objects in various functional categories. B: Number of differentially expressed genes annotated in functional databases. C: Inter-sample expression and Pearson correlation test chart. Note: In the lower left corner is the scatter plot of expression between samples. The abscissa is log2 (FPKM) and the ordinate is log2 (FPKM). The upper right corner is the correlation thermogram between samples. The color represents the degree of correlation between samples. The size of the number also represents the degree of correlation between different samples. In the middle is the expression density curve of each sample. The abscissa is $\log 10$ (FPKM), and the ordinate is the corresponding density value. The abscissa of the map is the name of the sequencing sample, and the ordinate is the name of the sequencing sample. 
Term type

KS

$1.5 \mathrm{E}-14$

0.0000042

0.000083

0.00013

molecular

function

0.00015

0.00016

0.0002

0.00033

0.00036

0.0004

$5.1 \mathrm{E}-22$

0.000000099

0.00000095

0.0000068

cellular component

biological process 0.000023 0.000087

0.00011

0.00014

0.00037

$8.8 \mathrm{E}-26$

0.0000001

0.000093

0.00029

0.00063

0.00071
GO.ID

Term

Annotated

Significant

GO:0004365 glyceraldehyde-3-phosphate... GO:0033218 amide binding

GO:0004298 threonine-type endopeptidase... GO:0016168 chlorophyll binding

GO:0046912 transferase activity, transferring...

GO:0004129 cytochrome-c oxidase activity GO:0004096 catalase activity

GO:0051536 iron-sulfur cluster binding

GO:0016491 oxidoreductase activity

GO:0003735 structural constituent of ribosome GO:0090406 pollen tube

GO:0009538 photosystem I reaction center GO:0071541 eukaryotic translation initiation... GO:0015935 small ribosomal subunit GO:0030687 preribosome, large subunit precursor GO:0000276 mitochondrial proton-transporting... GO:0030427 site of polarized growth

0.00091

0.00121

0.00211

0.00293
GO:0005758 mitochondrial intermembrane space

GO:0009535 chloroplast thylakoid membrane GO:0005840 ribosome

GO:0016485 protein processing

GO:0009401 phosphoenolpyruvate-dependent...

GO:0006458 de novo' protein folding

GO:0006098 pentose-phosphate shunt

GO:1901564 organonitrogen compound metabo... GO:0006817 phosphate ion transport

GO:0045041 protein import into mitochondrial... GO:0050821 protein stabilization GO:0010207 photosystem II assembly GO:0006412 translation

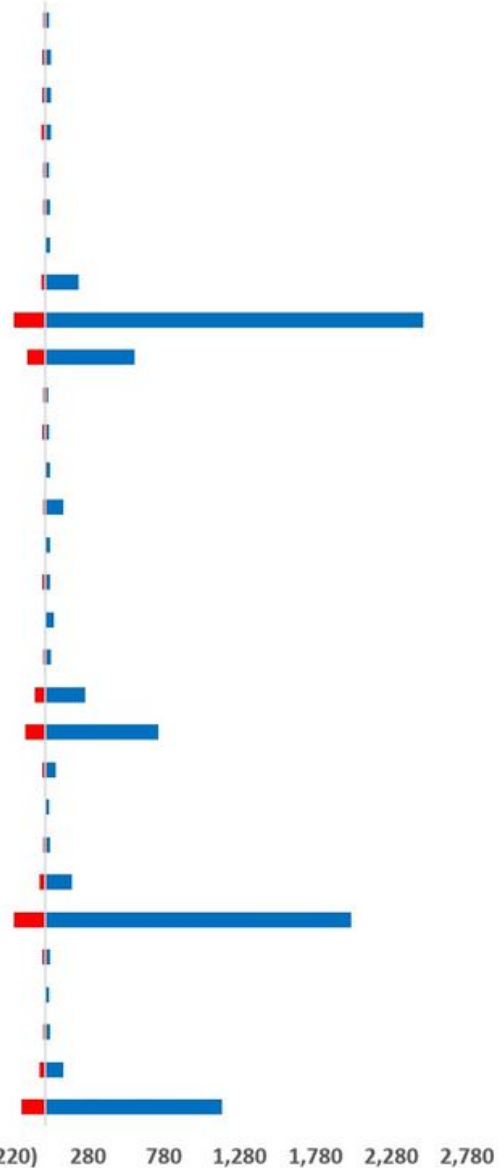

\section{Figure 4}




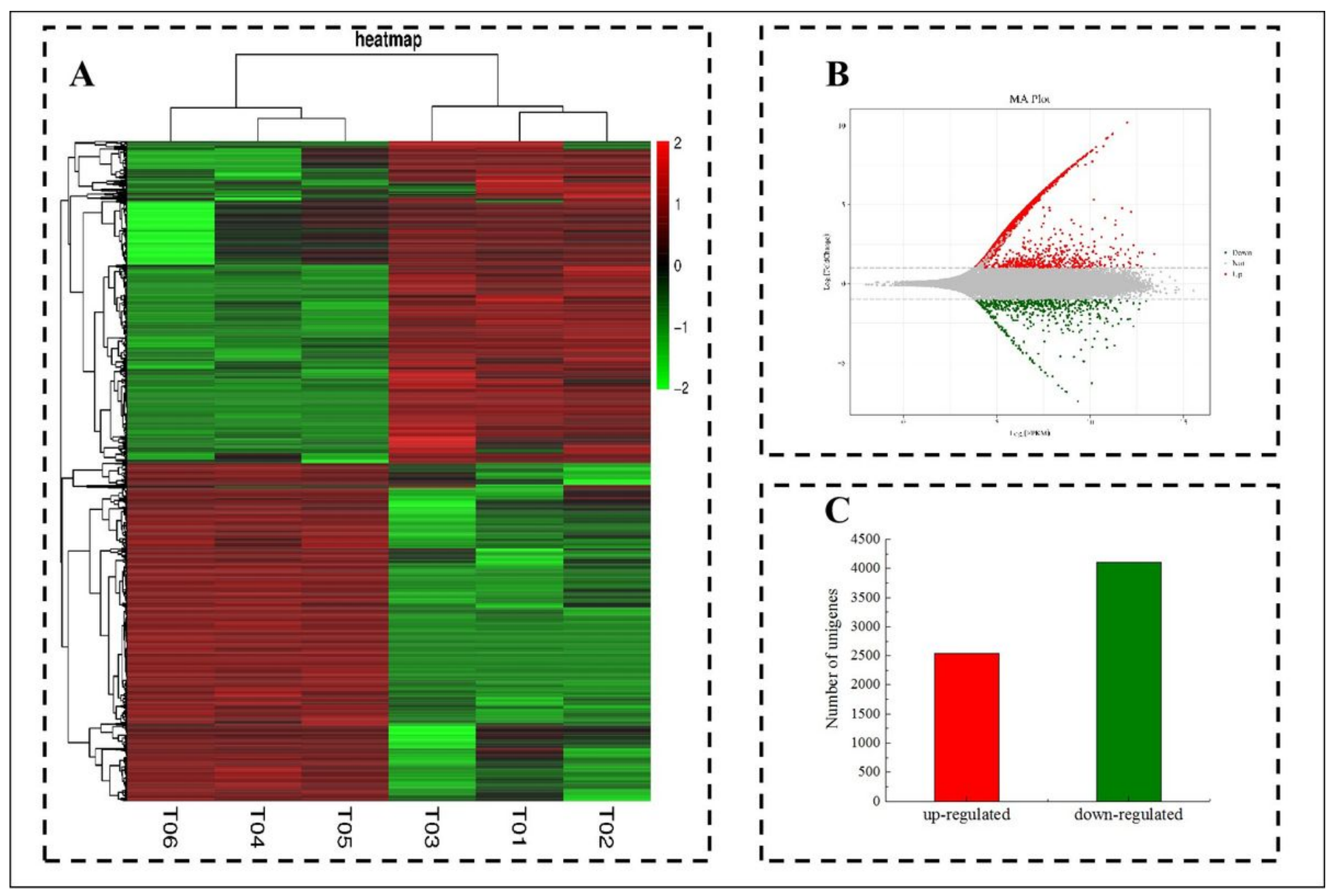

\section{Figure 5}

A: Cluster Map of Differentially Expressed Genes. Note: Different columns in the graph represent different samples, and different rows represent different genes. Color represents the level of gene expression in samples. $(\log 10(F P K M+1))$. B: Differentially expressed genes MA map. Note: Each point in the MA map of differentially expressed genes represents a gene. Log2 (FPKM) is the logarithmic value of the expression quantity in the two samples, and log2 (FC) is the logarithmic value of the multiple of gene expression difference between the two samples, which is used to measure the difference of expression quantity. The red dots in the picture represent genes that are significantly up-regulated, the green dots represent genes that are significantly down-regulated, and the gray dots represent genes that are not significantly different. C: Number of up-regulated and down-regulated genes 

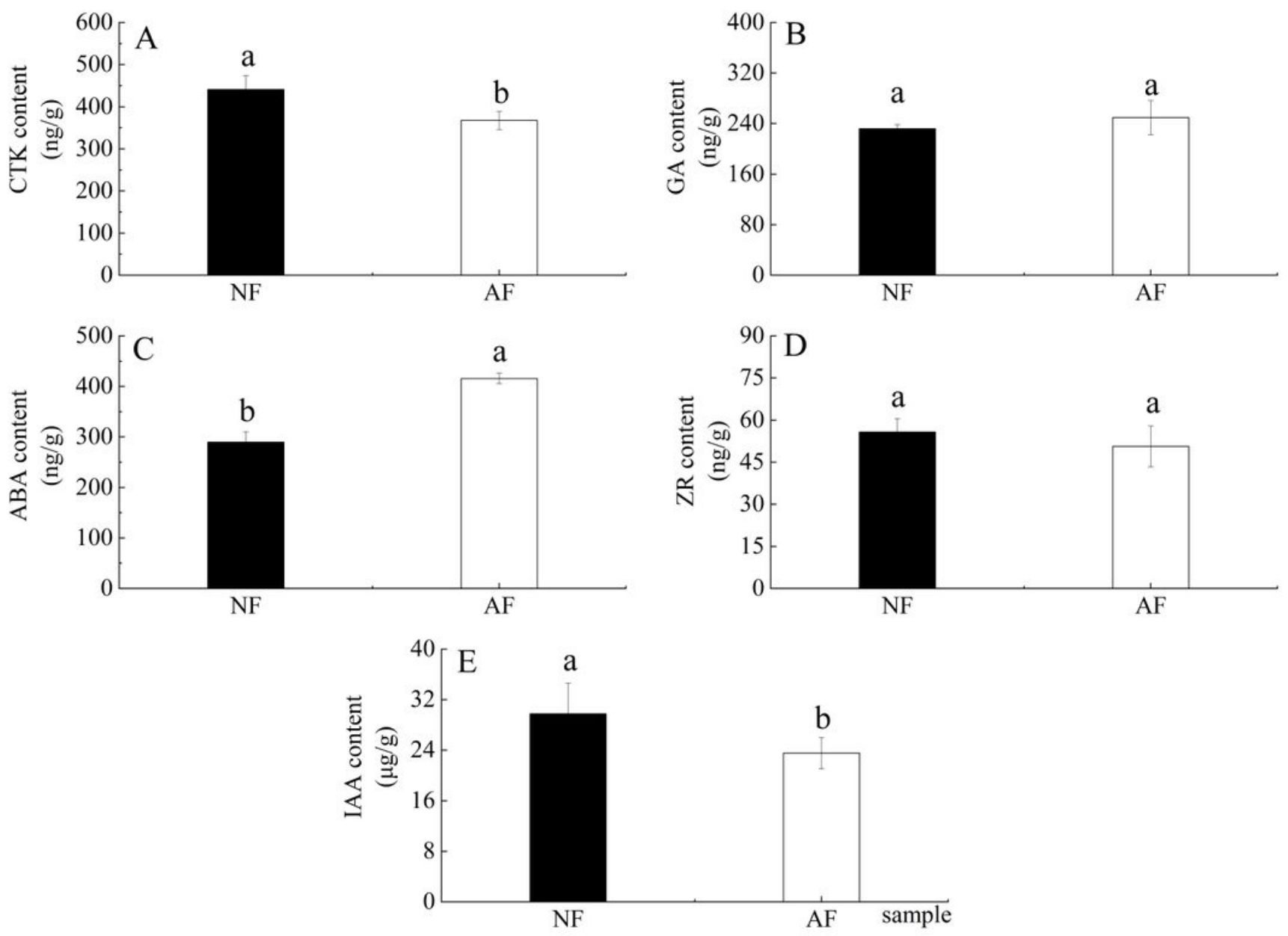

Figure 6

Endogenous hormone measurements. The contents of endogenous hormones, including CTK, GA, ABA ,IAA and ZR, between normal and abortion flowers were measured. Three independent samples collected from different flowers were used for endogenous hormone measurements 


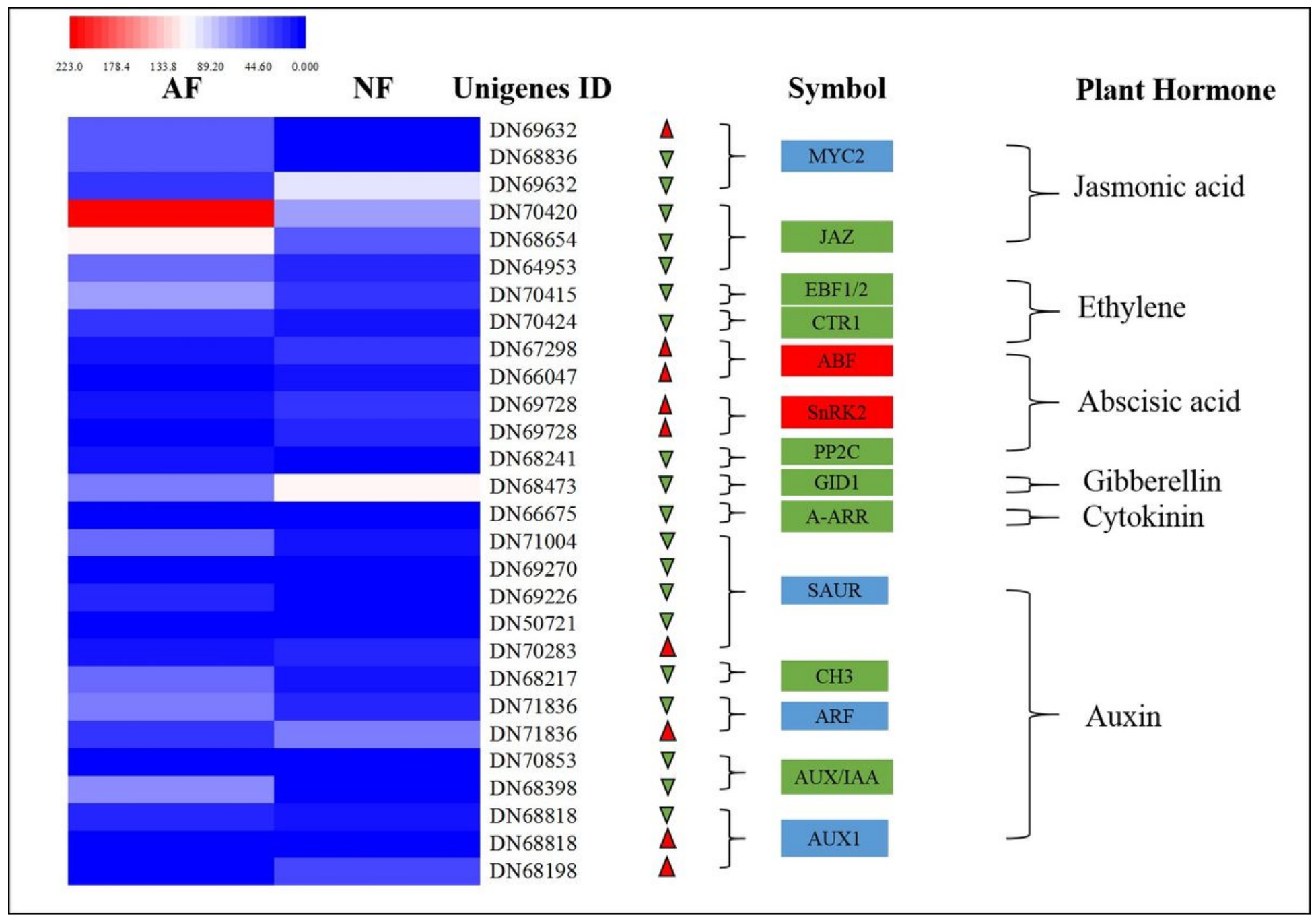

Figure 7

Heat map diagram of expression levels for DEGs annotated in the plant hormone signal transduction pathways analyzed by KEGG. 

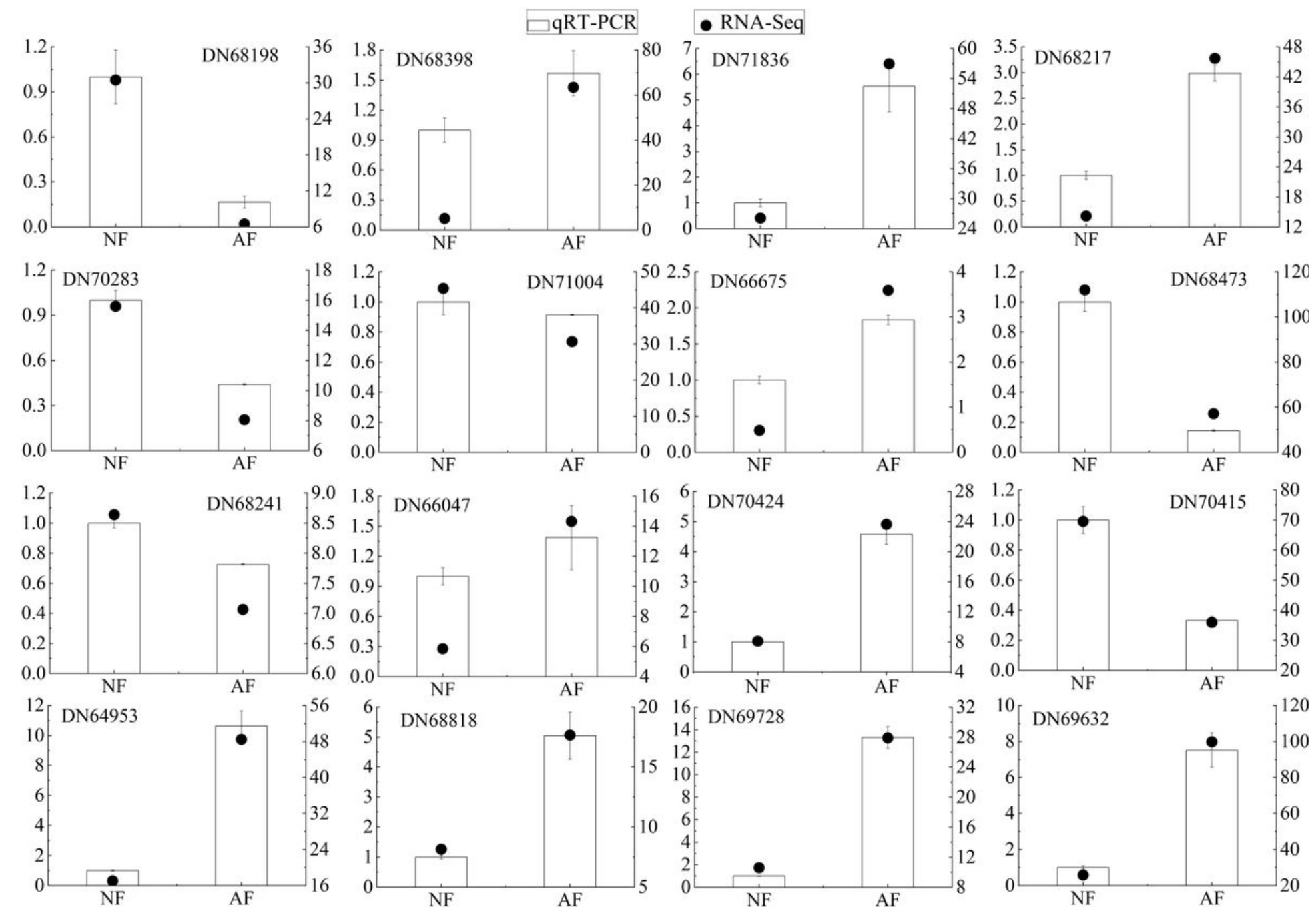

Figure 8

qRT-PCR confirmed 16 candidate genes between two treatments: NF and AF. The left $Y$ axis represents relative gene expression detected by qRT-PCR, the right $Y$ axis represents gene expression detected by RNA-Seq, and the $X$ axis represents different treatments.

\section{Supplementary Files}

This is a list of supplementary files associated with this preprint. Click to download.

- completedir.rar

- AdditionalFile.docx 